Федяй І.О., Маркіна Т.Ю., 2019

УДК 595.754 (477)

Федяй I.O.: http://orcid.org/0000-0002-7171-1622

Маркіна T.Ю.: http://orcid.org/0000-0002-6313-9814, Scopus Researcher ID56736553600

\title{
ДЕЯКІ ОСОБЛИВОСТІ СЕЗОННИХ ЦИКЛІВ НАПІВТВЕРДОКРИЛИХ (HETEROPTERA) УРБОЦЕНОЗІВ МІСТА ХАРКОВА
}

\author{
(C) Федяй I.О., Маркіна Т.Ю. \\ Харківський національний педагогічний університет імені Г.С. Сковороди, м. Харків \\ e-mail: razira1983@gmail.com \\ t.yu.markina@gmail.com
}

https://doi.org/10.34142/ 2708-583X.2019.21.13

\begin{abstract}
Наведено дані щзодо окремих характеристик життєвих ииклів напівтвердокрилих (Heteroptera), зареєстрованих в урбоиенозах м. Харкова. За кількістю генераиій виділено три, а на основі зимуючою стадіі - $n$ 'ять фенологічних груп. На стадії імаго зимують 114 видів (69,51\% всієї гетероптерофауни), з яких більшість видів належить до родин Lygaeidae (37), Miridae (14) ma Pentatomidae (22 види), Nabidae, Tingidae ma Rhopalidae (no ciм видів кожне). На стадії яйия зимує 42 види (25,61\%), головним чином з родини Miridae (34 види), менше - Lygaeidae, Nabidae, Rhopalidae (по два-три види кожне). На стадї личинки зимують лише чотири види (2,44\%) з родин Pentatomidae (3) ma Reduviidae (1 вид). В стадіях імаго і личинки, яєиь і личинки зимують по два види з кожної групи. Невелике число таких видів може пояснюватись тим, що умови для зимівлі у иих стадіях є менш сприятливими в помірних широтах (Східна Украӥна). До групи моновольтинних віднесено 107 видів клопів $(65,24 \%)$. Бівольтинні та полівольтинні групи представлені відповідно 32 (19,51\%) та 24 (14,63\% всієї гетероптерофауни) видами. Для Coriomeris denticulatus кількість поколінь за рік не встановлена.
\end{abstract}

Ключові слова: Неtеroptera, види, кількість генерачій, зимуюча стадія, урбоченози, Харків, Украӥна.

Весь цикл розвитку напівтвердокрилих, починаючи з фази яйця і закінчуючи дорослою фазою, що досягла статевої зрілості, позначається поняттям покоління або генерація. ÏÏ тривалість змінюється в значних межах і залежить від двох основних чинників спадкової ритміки життє-вого циклу і впливу зовнішніх факторів середовища. Загалом, життєві цикли більшості видів напівтвердокрилих та їх фенологія в умовах Східної Свропи (в т.ч. і в Україні) вивчені 3 різною повнотою, але головним чином в природних біотопах $[1-4,6-10,13,15$, 16]. Так, більшість клопів-щитників мають зимову факультативну імагінальну діапаузу. В природних умовах лише деякі види можуть мати більше одного покоління за вегетаційний сезон. Проте, в силу різних причин, може відбуватися редукція числа поколінь, $\mathrm{i}$ популяції, що живуть у високих i середніх широтах, як правило, переходять до моновольтинізму. Основними факторами, що обмежують кількість поколінь, виступають їжа i температура. Так, для завершення онтогенетичного циклу, напів-твердокрилим необхідна різна сума ефективних температур, тому в помірних широтах вони зазвичай дають тільки одне покоління за рік, тоді як на півдні до двох-трьох [3, 4].

Невелике число видів, що вступають в зимову діапаузу в личинкової стадії пояснюється, ймовірно, тим, що вони менш сприятливі для зимівлі в 
помірних широтах [1]. Окремі групи складають види, що зимують на стадії яйця або змішаних зимуючих фаз личинки та імаго чи яйця та личинки.

Для урбоценозів України такі дані відсутні, хоча умови в них можуть в певній мірі відрізнятись від таких у природних ценозах (наприклад температурний режим). Метою нашої роботи було уточнення особливостей життєвих циклів клопів, їх можливі зміни для окремих видів в умовах мегаполісу (на прикладі м. Харкова).

\section{МАТЕРІАЛИ І МЕТОДИ}

Матеріалом для досліджень були власні спостереження та обліки клопів в урбоценозах м. Харкова в період 2016-2018 рр. - 3 початку квітня до середини жовтня. Комах збирали стандартними методами косіння ентомологічним сачком, грунтовими пастками Барбера та вручну на рослинах, чагарниках і в грунтовій підстілці. При обліках реєстрували присутність різних стадій розвитку, особливості їх фенології та чисельність.

Класифікація підряду наведена за каталогом напівжорсткокрилих Палеарктики [17-20]. Характеристика життєвих циклів та фенології основних видів дана на основі як власних даних щодо реєстрації різних фаз клопів в онтогенезі, так і відомостей 3 ряду наукових публікацій $[1-5,8-12$, 14-16, 21].

\section{РЕЗУЛЬТАТИ ТА ÏХ ОБГОВОРЕННЯ}

Всього в урбоценозах м. Харкова виявлено 164 види клопів 3113 родів і
16 родин, які відрізняються кількістю генерацій та зимуючою стадією (табл. 1,2 , рис. 1).

Більшість клопів, зареєстрованих в урбоценозах м. Харкова, зимують на стадії імаго - 114 видів $(69,51 \%$ всіх Heteroptera) 314 родин: Acanthosomatidae, Anthocoridae, Aradidae, Berytidae, Coreidae, Cydnidae, Nabidae, Pyrrhocoridae, Rhopalidae, Scutelleridae, Tingidae, більшість видів Lygaeidae i Pentatomidae та окремих Miridae (головним чином 3 родів Lygus та Orthops) (табл. 1, рис. 1). Їх основу складають представники родин Lygaeidae (37), Miridae (14) та Pentatomidae (22 види), Nabidae, Tingidae та Rhopalidae (по сім видів кожне). Такі родини як Coreidae, Cydnidae, Anthocoridae, Scutelleridae включають від трьох до п'яти видів, а інші - по одному виду.

Необхідно відмітити, що вцілому мегаполіси, спричиняючи руйнівну дію на природню біоту, в певній мірі можуть надавати унікальні умови для збереження та розмноження окремих видів комах. Клопи, що зимують на стадії імаго, широко використовують будівлі, як місце схованки. Впродовж наших досліджень у приміщеннях університету, що взимку не використовуються спостерігалось масове скупчення імаго Lugaeus equestris (Linnaeus, 1758). 3 початку жовтня, зі зниженням температури до $+10^{\circ} \mathrm{C}$ клопи збирались у приміщенні. У середньому їх кількість складала до 300 особин. Нами було визначено їх життєздатність після виходу 3 діапаузи. Показники були достатньо 
високі (63\%), що свідчить про сприятливі умови зимівлі. Визначення статевої структури показало, що 52\% були самці, 48\% - самки. Таким чином можна стверджувати, що Lugaeus equestris добре пристосувався до умов міста, і його чисельність в подальшому може збільшуватися.

На стадії личинки зимують всього 4 види $(2,44 \%)$ з родини Pentatomidae Pentatoma rufipes (Linnaeus, 1758), Piezodorus lituratus (Fabricius, 1794), Peribalus strictus (Fabricius, 1803); a також Reduviidae - Reduvius personatus (Linnaeus, 1758) (табл. 1, рис. 1).

На стадії імаго та личинки зимують тільки два види $(1,22 \%) 3$ родини Lygaeidae - Kleidocerys resedae (Panzer, 1797) та Reduviidae Rhynocoris (Rhynocoris) iracundus (Poda, 1761) (табл. 1, рис. 1).
На стадії яйця зимують 42 види (25,61\%). Це більшість представників родини Miridae (36 видів) і деякі види 3 родини Coreidae - Coriomeris denticulatus (Scopoli, 1763); родина Lygaeidae представлена такикми видами: Holcocranum saturejae (Kolenati, 1845), Nysius helveticus (HerrichSchäffer, 1850) и N. thymi (Wolff, 1804); Nabidae - Himacerus (Himacerus) apterus (Fabricius, 1798) и Nabis (Nabis) pseudoferus Remane, 1949; Rhopalidae Chorosoma gracile Josifov, 1968 и Myrmus miriformis (Fallén, 1807) (табл. 1, рис. 1).

На стадії яйця та личинки зимують два види $(1,22 \%)$ з родини Alydidae - Alydus calcaratus (Linnaeus, 1758) та Tingidae - Kalama tricornis (Schranck, 1801) (табл. 1, рис. 1).

Стадії зимівлі видів напівтвердокрилих різних родин в умовах м. Харкова

\begin{tabular}{|c|l|c|c|c|c|c|}
\hline $\begin{array}{c}\text { № } \\
\text { 3/п }\end{array}$ & \multicolumn{1}{|c|}{ Родина } & Яйце & Личинка & $\begin{array}{c}\text { Яйце та } \\
\text { личинка }\end{array}$ & Імаго & $\begin{array}{c}\text { Личинка та } \\
\text { імаго }\end{array}$ \\
\hline 1. & Acanthosomatidae & - & - & - & 1 & - \\
\hline 2. & Alydidae & - & - & 1 & - & - \\
\hline 3. & Anthocoridae & - & - & - & 3 & - \\
\hline 4. & Aradidae & - & - & - & 1 & - \\
\hline 5. & Berytidae & - & - & - & 2 & - \\
\hline 6. & Coridae & - & - & - & 5 & - \\
\hline 7. & Cydnidae & 3 & - & - & 4 & - \\
\hline 8. & Lygaeidae & 34 & - & - & 37 & 1 \\
\hline 9. & Miridae & 2 & - & - & 7 & - \\
\hline 10. & Nabidae & - & 3 & - & 22 & - \\
\hline 11. & Pentatomidae & - & - & - & 1 & - \\
\hline 12. & Pyrrhocoridae & - & 1 & - & - & 1 \\
\hline 13. & Reduviidae & 2 & - & - & 7 & - \\
\hline 14. & Rhopalidae & - & - & - & 3 & - \\
\hline 15. & Scutelleridae & - & - & 1 & 7 & - \\
\hline 16. & Tingidae & 42 & 4 & 2 & 114 & 2 \\
\hline & \multicolumn{1}{|c|}{ Bсього } & & & \\
\hline
\end{tabular}




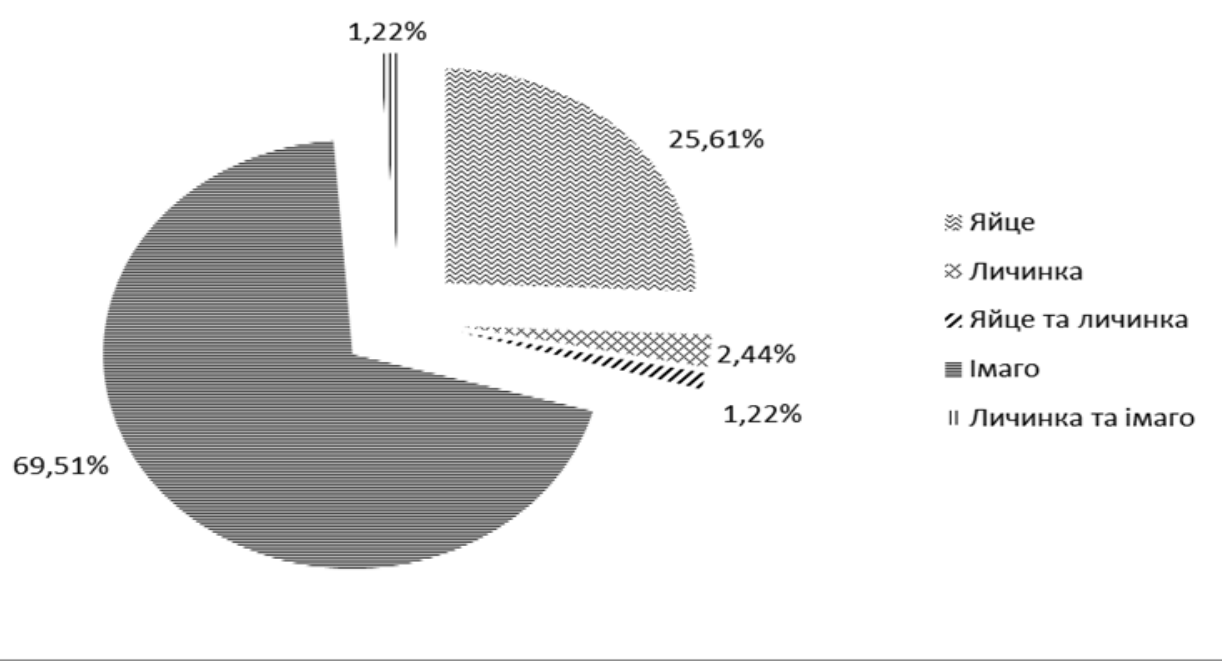

Puc. 1. Співвідношення (\%) видів клопів, що зимують на різних стадіях онтогенезу на території м. Харкова

За кількістю генерацій, напівтвердокрилих, що зареєстровані в урбоценозах м. Харкова, можна розділити на три основні групи (табл. 2):

1. Моновольтинні види - мають одне покоління на рік. Виявлено 107 видів $(65,24 \%$ всіх Heteroptera) 3 родин Lygaeidae (30), Miridae (25), Pentatomidae (23), Nabidae (8), Tingidae (5), Cydnidae (4), Coreidae, Scutelleridae (по три), Berytidae, Rhopalidae (по два), Acanthosomatidae та Reduviidae (по одному виду).

2. Бівольтинні види - мають два покоління на рік. Всього відзначено 32 види (19,51\%) - Miridae,
(14), Lygaeidae (7), Tingidae (3), Pentatomidae та Rhopalidae (по два), Alydidae, Anthocoridae, Coreidae та Nabidae (по одному виду кожна).

3. Полівольтинні види, що мають більше двох поколінь на рік. Сюди відносяться 25 видів (14,63\%) 3 родин: Miridae (8), Lygaeidae, Rhopalidae (по 5), Anthocoridae, Coreidae (по два), Aradidae, Pyrrhcoridae та Reduviidae (по одному виду кожна).

Для виду Coriomeris denticulatus (Scopoli, 1763) (родина Coreidae) життєвий цикл в умовах урбоценозів невиявлений, але можна припустити, що він моновольтинний.

Таблиия 2

Кількість видів та їх співвідношення за групами напівтвердокрилих (Heteroptera) 3 різним числом генерацій

\begin{tabular}{|l|c|c|}
\hline \multicolumn{1}{|c|}{ Групи } & $\begin{array}{c}\text { Кількість } \\
\text { видів }\end{array}$ & Співвідношення (\%) \\
\hline Моновольтинні & 107 & 65,24 \\
\hline Бівольтинні & 32 & 19,51 \\
\hline Полівольтинні & 24 & 14,63 \\
\hline Кількість поколінь на рік невідома & 1 & 0,62 \\
\hline Всього & 164 & 100 \\
\hline
\end{tabular}




\section{ВИСНОВКИ}

У результаті проведених досліджень в урбоценозах м. Харкова виявлено 164 види клопів з 113 родів і 16 родин.

За кількістю генерацій виділено три основні групи. До моновольнинних віднесено 107 видів клопів $(65,24 \%)$. Бівольтинні та полівольтинні групи представлені відповідно 32 (19,51\%) та 24 (14,63\% всієї гетероптерофауни) видами. Для виду Coriomeris denticulatus кількість поколінь за рік не встановлена.

За зимуючою стадією виділено п'ять фенологічних груп. На стадії імаго зимують 114 видів $(69,51 \%$ всієї гетероптерофауни), 3 яких більшість видів належить до родин Lygaeidae (37), Miridae (14) та Pentatomidae (22 види), Nabidae, Tingidae та Rhopalidae (по сім видів кожне). На стадії яйця зимує 42 види $(25,61 \%)$, головним чином 3 родини Miridae (34 види), менше - Lygaeidae, Nabidae, Rhopalidae (по два-три види кожне). На стадії личинки зимують лише чотири види $(2,44 \%) \quad 3$ родин Pentatomidae (3) та Reduviidae (1 вид). В стадіях імаго і личинок та яєць i личинок зимують по два види з кожної групи. Невелике їх число може пояснюватись тим, що умови для зимівлі у цих стадіях $є$ менш сприятливими в помірних широтах.

\section{Список використаних джерел}

1. Kerzhner Y.M., Yachevskyi T.L. (1964) Otriad Hemiptera (Heteroptera) - poluzhestkokrylye, yly klopy. Opredelytel nasekomykh evropeiskoi chasty SSSR. M.-L.: Nauka. T. 1.

2. Musolyn D.L. (2011) Shchytnyky (Heteroptera: Pentatomoidea): raznoobrazye sezonnykh adaptatsyi, mekhanyzmov kontrolia sezonnoho razvytyia y reaktsyi na yzmenenye klymata : dyss. d-ra byol. nauk : 03.02.05 / Sankt-Peterb. hos. lesotekhn. un-t Sankt-Peterburh.

3. Saulych A.Kh., Musolyn D.L. (2007) Vremena hoda: raznoobrazye sezonnykh adaptatsyi y эkolohycheskykh mekhanyzmov kontrolia sezonnoho razvytyia poluzhestkokrylykh (Heteroptera) v umerennom klymate. Stratehyy adaptatsyi nazemnykh chlenystonohykh k neblahopryiatnym uslovyiam sredy: Tr. Byol. NYY SPbHU.

4. Saulych A.Kh., Musolyn D.L. (2014) Sezonnye tsykly shchytnykov (Heteroptera, Pentatomidae) umerennoho poiasa: raznoobrazye y rehuliatsyia. Эntomolohycheskoe obozrenye. XCIII (2): 263 302.

5. Puchkov V.H. (1961) Do ekolohii malovyvchenykh vydiv napivterdokrylykh Evropeiskoi chastyny SRSR. Soobshch. II. Pratsi instytutu zoolohii AN Ukr. RSR. T. 17. S. 86-93.

6. Puchkov V.H. (1961) Korysni dlia silskoho i lisovoho hospodarstva khyzhi napivtverdokrylykh SRFSR. Pratsi instytutu zoolohii AN Ukr. RSR. T. 17. S. 7-18.

7. Puchkov V.H. (1961) Slipniaky (Heteroptera, Miridae) Poltavskoi oblasti. Pratsi instytutu zoolohii AN Ukr. RSR. T. 17. S. 71-85.

8. Puchkov V.H. (1966) Hlavneishye klopyslepniaky - vredytely selskokhoziaistvennykh kultur. Kyev: Naukova dumka.

9. Puchkov V.H. (1974) Beretydy, chervonoklopy. pyezmatydy, podkornyky y tynhydы. Kyev: Naukova dumka.

10. Puchkov V.H. (1986) Poluzhestkokrylye semeistva Rhopalidae (Heteroptera) fauny SSSR. L.: Nauka.

11. Puchkov V.H. (1961) Shchytnyky. Fauna Ukrainy. Kyiv: Vyd-vo AN Ukrainskoi RSR. T. 21. Vyp. 1.

12. Puchkov V.H. (1962) Kraiovyky. Fauna Ukrainy. Kyiv: Vyd-vo AN Ukrainskoi RSR. T. 21. Vyp. 2.

13. Puchkov V.H. (1965) Shchytnyky Srednei Azyy (Hemiptera, Pentatomoidea). Frunze: Ylym (Yzd-vo AN Kyrhyzskoi SSR).

14. Puchkov V.H. (1969) Liheidy. Fauna Ukrainy. Kyiv: Vyd-vo AN Ukrainskoi RSR. T. 21, vyp. 3.

15. Puchkov P.V. (1987) Khyshchnetsы. Fauna Ukrayny. Poluzhestkokrыlыe. Kyev: Naukova dumka. T. 21, vыр. 5.Wagner E.L., Weber H.H. (1964) Heteroptêres Miridae. Fauna de France. No. 67.

16. Catalogue of the Heteroptera of Palearctic Region (1996). Cimicomorpha I. Aukema B \& Rieger Ch. (Eds). 
17. Catalogue of the Heteroptera of the Palaearctic Region // The Netherlands Entomol. Society. Amsterdam (2001). Vol. 4.

18. Catalogue of the Heteroptera of the Palaearctic Region // The Netherlands Entomol. Society. Amsterdam (2006). Vol. 5.
19. Kerzhner I.M., Josifov M. (1999) Miridae. In: Catalogue of the Heteroptera of Palearctic Region. Cimicomorpha II. Aukema B \& Rieger Ch. (Eds). 3, 1-557.

20. Southwood T.R.E., Leston D. (1959). Land and water bugs of the British Isles. F. Warne \& CO. LTD, London \& New York, 1-436.

UDC595.754 (477)

\title{
SOME FEATURES OF SEASON CYCLES OF REPRESENTATIVES OF THE SUBORDER OF TRUE BUGS (HETEROPTERA) IN URBAN CENOSES OF KHARKIV
}

\author{
Fedyay I.A., Markina T.Yu.
}

The article deals with the analysis of the data on the individual characteristics of the life cycles of Heteroptera recorded in the urban cenoses of Kharkiv. In terms generations, three phenological groups were distinguished and five phenological groups - on the basis of the wintering stage. At the imago stage, 114 species hibernate $(69.51 \%$ of the entire heteropterofauna), of which most species belong to the families Lygaeidae (37), Miridae (14) and Pentatomidae (22 species), Nabidae, Tingidae, and Rhopalidae (seven species each). At the egg stage, 42 species winter (25.61\%), mainly from the Miridae family (34 species), fewer - Lygaeidae, Nabidae, Rhopalidae (two or three species each). At the larval stage, only four species (2.44\%) from the Pentatomidae (3) and Reduviidae (1 species) families hibernate. Two species from each group hibernate at the stages of imago and larvae, eggs and larvae. A small number of such species can be explained by the fact that the conditions for wintering at these stages are less favorable in temperate latitudes (Eastern Ukraine). The group of monovoltines includes 107 species of bugs (65.24\%). The bivoltine and multivoltine groups are represented by 32 (19.51\%) and 24 (14.63\% of the entire hetero-fauna) species, respectively. As for Coriomeris denticulatus, the number of their generations per year has not been established.

Key words: Heteroptera, species, number of generations, wintering (hibernating) stage, urban cenoses, Kharkiv, Ukraine.

Стаття надійшла 27. 09. 2019 р. Рекомендована до друку на засіданні редакційної колегії після рецензуванн 